AperTO - Archivio Istituzionale Open Access dell'Università di Torino

\title{
Analytical Approaches in Fatal Intoxication Cases Involving New Synthetic Opioids
}

\section{This is a pre print version of the following article:}

Original Citation:

\section{Availability:}

This version is available http://hdl.handle.net/2318/1685940

since 2019-01-07T17:16:56Z

Published version:

DOI:10.2174/1389201019666180405162734

Terms of use:

Open Access

Anyone can freely access the full text of works made available as "Open Access". Works made available under a Creative Commons license can be used according to the terms and conditions of said license. Use of all other works requires consent of the right holder (author or publisher) if not exempted from copyright protection by the applicable law. 


\section{Analytical approaches in fatal intoxication cases involving new}

\section{synthetic opioids}

Enrico Gerace $^{1^{*}}$, Alberto Salomone ${ }^{1}$ and Marco Vincenti ${ }^{1,2}$

${ }^{1}$ Centro Regionale Antidoping “A. Bertinaria”, Regione Gonzole 10/1, 10043 Orbassano, Turin, Italy

${ }^{2}$ Dipartimento di Chimica, Università degli Studi di Torino, via P. Giuria 7, 10125 Turin, Italy

"Corresponding author: Enrico Gerace, $\mathrm{PhD}$

Centro Regionale Antidoping “A. Bertinaria”,

Regione Gonzole, 10/1 - 10043 Orbassano (Turin) - Italy

Tel: +3901190224249 , Fax: +3901190224242 , Mobile: +393393795125

E-mail address: enrico.gerace@ antidoping.piemonte.it

Keywords: New Psychoactive Substances; Synthetic Opioids; Fentanyl analogues; U-47700; AH7941, Intoxication; Postmortem. 


\section{ABSTRACT}

Synthetic opioids are compounds that were created to act as agonists for the opioid receptors. Novel synthetic opioids include various analogs of fentanyl (e.g., acetylfentanyl, acryloylfentanyl, carfentanil, furanylfentanyl, 4-fluorobutyrylfentanyl and ocfentanil) and newly emerging non-fentanyl compounds with different chemical structures, such as AH-7921, MT-45, and U-47700. In the last years, these drugs have rapidly emerged on the recreational drug market, and their abuse has been increasing worldwide. Due to the high potency and the low dose required to produce the desired effects, the risk of overdose for these compounds is high, with severe health implications. Several fatal intoxication cases related to the abuse of synthetic opioids were recently reported in the literature. As a consequence, the detection of these compounds in biological samples is crucial in order to understand their concentration and distribution in body fluids.

We overviewed the analytical approaches reported in the literature for the investigation of synthetic opioids in postmortem sample, with special emphasis given to real cases of lethal intoxication. 


\section{INTRODUCTION}

For many years, the spectrum of abused drugs amounted to few substances, whereas in recent years a huge upsurge of new psychoactive substances (NPS) has been observed. Although most NPS fall into the categories of synthetic cannabinoids and designer cathinones, recent years have seen the appearance of novel synthetic opioids on the recreational drug market with a progressive increase in their abused consumption. Many synthetic opioids are derivatives of a single pharmacological substance, namely fentanyl. However, new synthetic opioids such as AH-7921, MT-45, and U-47700, have chemical structures totally distinct from any known therapeutic or recreational drug. These substances are sold as 'research chemicals' mainly through internet shops and used as substitutes of controlled opioids, but they are also sold under the guise of heroin to unaware users, with high risk of severe intoxication [1]. The motivations for the use of these new drugs include their legal status, ready availability, low cost, users' testing curiosity or preference for their particular pharmacological properties, and the intention to avoid detection [2]. Furthermore, likewise to what has been reported for extasy users [3,4], it is very likely that "traditional drugs", e.g. heroin, are replaced or added with new designer opioids, so many drug addicts are unintentionally or unknowingly using synthetic fentanyl analogues. Since these street powders vary in composition and potency, their use often leads to intoxications and overdose fatalities. Thus, synthetic opioids represent a new trend in the recreational drug market and numerous cases of abuse, intoxication and deaths related to their consumption were recently described in the literature [5]. As a consequence, forensic and clinical laboratories worldwide are continuously requested to update their analytical procedures for the identification and quantification of these new drugs in various biological matrices. In the present article, the different analytical approaches used for the determination of synthetic opioids in post-mortem samples arising from fatal intoxication cases are reviewed. 


\section{FENTANYL ANALOGUES}

\section{Acetylfentanyl}

Acetylfentanyl (N-[1-phenethylpiperidin-4-yl]-N-phenylacetamide) is a potent synthetic opioid analgesic that has been increasingly available worldwide during the last years, despite it has no approved medical or veterinary use, but it is rather consumed illicitly around the world as a substitute of its controlled precursor, fentanyl, as well as heroin or other related substances in opioid-dependent individuals [6]. Acetylfentanyl is available online or in retail shops and it is usually delivered as a powder, or in tablets, or pre-loaded paper doses (blotters), but liquid and injectable formulations have also been reported [6, 7]. Although it was first synthesized in 1968, it has gained the attention of authorities worldwide only recently due to the occurrence of human intoxications and fatalities; in fact, it has a significant potential for overdose [8]. Its use has been reported in the Unites States, Europe, Australia, and Japan.

McIntyre et al. quantified acetylfentanyl in several matrices by gas chromatography-mass spectrometry (GCMS) [9] in a fatal case occurring in San Diego (USA). Initial toxicology screening were performed by ELISA and turned out positive for the presence of fentanyl. Subsequently, acetylfentanyl was detected and confirmed by GC-selected ion monitoring (SIM)-MS using fentanyl- $d_{5}$ as the internal standard for quantification. Sample preparation consisted in a double liquid-liquid extraction (LLE) with 1-chlorobutane after alkalization with concentrated ammonium hydroxide. The limit of detection (LOD) and quantitation (LOQ) values were determined as 50 and $100 \mathrm{ng} / \mathrm{mL}$, respectively. Peripheral- and central blood concentrations of $260 \mathrm{ng} / \mathrm{mL}$ and $250 \mathrm{ng} / \mathrm{mL}$ acetylfentanyl were measured. The drug concentration was $1,000 \mathrm{ng} / \mathrm{kg}$ in liver, $240 \mathrm{ng} / \mathrm{mL}$ in the vitreous humor, and 2,600 ng/mL in urine.

A similar approach was adopted by Fort et al. in two intoxication cases [10]. A GC-SIM-MS method was created for the accurately quantification of acetylfentanyl using the ${ }^{13} \mathrm{C}$-substituted internal standard ${ }^{13} \mathrm{C}_{6^{-}}$ acetylfentanyl. The ions monitored were m/z 231146 and 188 (qualifier ions) for acetylfentanyl, and m/z

237 (quantifier ion) and 152 for ${ }^{13} \mathrm{C}_{6}$-acetylfentanyl. Depending on the circumstances, the drug was determined in blood samples, liver, brain, vitreous humor, and urine. In individual 1, acetylfentanyl concentrations were found as follows: heart blood $285 \mathrm{ng} / \mathrm{mL}$, femoral blood $192 \mathrm{ng} / \mathrm{mL}$, liver 1,100 ng/g, 
brain $620 \mathrm{ng} / \mathrm{g}$, and urine 3,420 ng/mL. In individual 2, , acetylfentanyl concentrations were as follows: heart blood $210 \mathrm{ng} / \mathrm{mL}$, femoral blood $255 \mathrm{ng} / \mathrm{mL}$, urine 2,720 ng/mL, and vitreous humor $140 \mathrm{ng} / \mathrm{mL}$.

Another case of intoxication attributed to acetylfentanyl was reported by Takase et al. [11]. Screening analyses were performed on $1 \mathrm{~mL}$ of cardiac blood, gastric contents, and urine using both GC-MS and liquid chromatography-tandem mass spectrometry (LC-MS/MS) after an extraction procedure by solid phase extraction (SPE). For confirmation analysis, $500 \mu \mathrm{L}$ of cardiac blood was extracted with ethyl acetate after the addition of potassium carbonate. Quantitative analysis was performed by GC-MS using the standard addition method. Acetylfentanyl was detected in blood at a concentration of $270 \mathrm{ng} / \mathrm{mL}$.

A dedicated LC-MS/MS method was developed by Yonemitsu et al. in a fatal poisoning case by intravenous injection of acetylfentanyl and 4-methoxy PV8 [12]. Acetylfentanyl was initially identified in an urine sample of the deceased by GC-MS and LC-MS with the mass spectrometers operating in scan mode. Confirmation analysis was performed on femoral blood, urine and gastric content by LC-MS/MS operating in selected reaction monitoring (SRM). Diazepam-d5 was used as the internal standard and the samples were extracted using a QuEChERS extraction salt containing anhydrous magnesium sulfate and anhydrous sodium acetate. Acetylfentanyl concentrations of 153,240 , and $880 \mathrm{ng} / \mathrm{mL}$, respectively, were found in the femoral vein blood, urine, and gastric contents.

An ultra-high performance liquid chromatography (UHPLC)-MS/MS procedure was used to confirm and quantify acetylfentanyl in autopsy blood, urine, liver, and vitreous fluid in another fatal intoxication case [13]. Screening analyses for the detection of a broad panel of drugs and metabolites were executed on urine with different techniques, including enzyme immunoassay (EIA), GC-MS after extraction with Toxi-Tube A tubes, and liquid chromatography-time-of-flight mass spectrometry (LC-TOF/MS) following LLE. For confirmation, the samples (blood, urine, liver, and vitreous fluid) were submitted to LLE at $\mathrm{pH}>9$ with a mixture of chlorobutane/acetonitrile 4:1. The instrumental analysis was performed by UHPLC/MS-MS using SRM and electrospray ionization (ESI) in positive mode. The SRM transitions for the detection and quantitation of acetylfentanyl were $\mathrm{m} / \mathrm{z} 323 \rightarrow 105,323 \rightarrow 188$ and $323 \rightarrow 77$. Acetylfentanyl concentrations recorded in subclavian blood, urine, liver, and vitreous fluid were $235 \mathrm{ng} / \mathrm{mL}, 234 \mathrm{ng} / \mathrm{mL}, 2,400 \mathrm{ng} / \mathrm{g}$ and $131 \mathrm{ng} / \mathrm{mL}$ respectively. 


\section{Acrylfentanyl}

Acrylfentanyl (N-phenyl-N-[1-(2-phenylethyl)piperidin-4-yl] prop-2-enamide) is a highly lipophilic analog of the therapeutic drug fentanyl with an affinity for the $\mu$-opioid receptor higher than fentanyl; its activity was reported to be more than 160 times higher than morphine [14]. This compound has no known uses, and is currently only found as a fentanyl derivative sold online as a new psychoactive substance. The drug has been typically seized as a liquid or a tablet, less frequently as a powder or inserted in capsule. It has been recently identified in seizures executed in a few north-european countries, including Denmark, Estonia, Finland, Latvia, and Sweden [15].

A recent publication reported a series of 40 fatal intoxication cases occurred in Sweden, in which the intake of the acrylfentanyl was ascertained to be the main - or a contributing - cause of death [14]. The method used to extract acrylfentanyl from the blood samples was LLE at $\mathrm{pH} 11$, after the addition of 1 M TRISbuffer and tert-butylmethylether (TBME). Analysis and quantification of acrylfentanyl in the blood extracts was performed by UHPLC-MS/MS using ESI in the positive mode and SRM for data acquisition. Two SRM transitions were programmed for acrylfentanyl detection, namely $\mathrm{m} / \mathrm{z} 335.20 \rightarrow 188.10$ as the quantifier and $\mathrm{m} / \mathrm{z} 335.20 \rightarrow 105.10$ as the qualifier transitions. Fentanyl- $d_{5}$ was used as the internal standard $(\mathrm{m} / \mathrm{z}$ $342.0 \rightarrow 188.0$ ). The recorded acrylfentanyl concentrations in blood ranged from 0.02 to $5.0 \mathrm{ng} / \mathrm{g}$.

\section{Butyrfentanyl and 4-fluorobutyrfentanyl}

Butyrfentanyl (N-phenyl-N-[1-(2-phenylethyl)-4-piperidinyl]-butanamide) and 4-fluorobutyrfentanyl (N-(4fluorophenyl)-N-[1-(2-phenylethyl)-4-piperidinyl]-butanamide) are further opioids analog to fentanyl with no recognized medical use. Although they were found to be less potent than fentanyl [16] they have recently become available in the illegal market and have been associated with abuse and severe intoxication cases [2, $5,16]$.

Staeheli et al. quantified butyrfentanyl in several biological matrices from a fatal intoxication case by LCMS/MS [17]. Initial toxicology screening was performed on urine by both cloned enzyme donor immunoassay (CEDIA®) and GC-MS after enzymatic conjugate cleavage using Helix pomatia. Femoral blood was additionally screened for drugs by an untargeted LC-ion trap MS/MS screening method after 
simple protein precipitation. Drug quantification in the femoral blood was performed by UHPLC-MS/MS using fentanyl- $d_{5}$ as the internal standard and the MS operating in the unscheduled SRM mode, with four transitions dedicated to the unlabeled butyrfentanyl and four transitions for the ${ }^{13} \mathrm{C}$ isotope of butyrfentanyl. For the latter confirmation analysis, the blood sample was LL-extracted in two steps with butyl acetate/ethyl acetate $(1: 1, \mathrm{v} / \mathrm{v})$, at $\mathrm{pH} 7.4$ and $\mathrm{pH} 13.5$ respectively. The method calibration proved to be linear within the concentration range $1-2,500 \mathrm{ng} / \mathrm{mL}$, with the lowest level corresponding to the LOQ for butyrfentanyl. A further investigation on butyrfentanyl metabolites was conducted in urine using a LC-high resolution (HR)MS time of flight mass spectrometer (TOF-MS). The butyrfentanyl concentration in femoral and heart blood collected 9 hours after the death were 66 and $39 \mathrm{ng} / \mathrm{mL}$, respectively.

Another fatal intoxication case involving butyrfentanyl was described by McIntyre et al. [18]. Using the same approach described before for acetylfentanyl [9], butyrfentanyl was successfully detected in peripheral blood (58 ng/mL), central blood (97 ng/mL), urine (670 ng/mL), vitreous humor $(40 \mathrm{ng} / \mathrm{mL})$, liver $(320 \mathrm{ng} / \mathrm{g})$ and gastric content $(170 \mathrm{mg}$ ) by a dedicated GC-SIM-MS method monitoring m/z 259 for the quantifier ion, 146 and 189 as the qualifier ions. The LOD was $\sim 2 \mathrm{ng} / \mathrm{mL}$ while the LOQ, fixed at the lowest calibration concentration, was $10 \mathrm{ng} / \mathrm{mL}$. In this case, acetylfentanyl was also detected in body fluids and tissues.

Two fatal cases involving 4-fluorobutyrfentanyl were reported by Rojkiewicz et al. [19]. 4fluorobutyrfentanyl was quantified in the autopsy material originating from two deceased subjects by means of LC-MS with the choice of fentanyl as the internal standard. The MS was operated in full scan mode between $\mathrm{m} / \mathrm{z} 100$ and m/z 650. The samples were sonicated at $\mathrm{pH} 9$ after the addition of TRIS-buffer and acetonitrile, then extracted by LLE by addition of ethylacetate. The calibration was linear for the concentration range 20-5,000 ng/mL; LOD and LOQ were calculated and reported as 7 and $12 \mathrm{ng} / \mathrm{mL}$, respectively. 4-fluorobutyrfentanyl was found in blood, urine, liver, and kidneys. Blood concentrations were $91 \mathrm{ng} / \mathrm{mL}$ (case 1) and $112 \mathrm{ng} / \mathrm{mL}$ (case 2).

\section{Furanylfentanyl and Carfentanil}

Furanylfentanyl (N-phenyl-N-[1-(2-phenylethyl)piperidin-4-yl]-2-furancarboxamide) and carfentanyl (methyl 1-(2-phenylethyl)-4-(N-propanylanilino)piperidine- 4-carboxylate) are highly potent $\mu$-opioid 
agonists with no prescription for human medical use. However, carfentanil is used in veterinary medicine (under the brand name Wildnil®) as a strong tranquilizer, to calm and immobilize large animal [20].

Seven cases of furanylfentanyl-related deaths have been recently reported by Guerrieri et al. [21]. The analytical approach based on LLE and LC-MS/MS analysis, previously used by the same Authors for the detection of acrylfentanyl in several intoxication cases, was adopted also for furanylfentanyl [21]. The flow rate for LC separation was set to $0.8 \mathrm{~mL} / \mathrm{min}$ with mobile Phase $\mathrm{A}(0.05 \%$ formic acid in $10 \mathrm{mM}$ ammonium formate), and B ( $0.05 \%$ formic acid in methanol) varying with a linear gradient from $2 \%$ B to $100 \% \mathrm{~B}$ in 3.0 min. Data acquisition was performed in SRM with two transitions for furanylfentanyl, i.e. $\mathrm{m} / \mathrm{z} 372.2 \rightarrow 188.1$ and $\mathrm{m} / \mathrm{z} 375.2 \rightarrow 105.1$ as the quantifier and qualifier. Furanylfentanyl was determined in post mortem femoral blood at concentrations ranging from 0.41 to $2.74 \mathrm{ng} / \mathrm{g}$.

Swanson et al. reported two fatal cases involving carfentanil and furanylfentanyl. The initial toxicology screening for the detection of common drugs was performed in postmortem blood, vitreous and/or urine specimens by immunoassay (ELISA) and full scan GC-MS [22]. The fentanyl cut-off concentration for the immunoassay was $2 \mathrm{ng} / \mathrm{mL}$. For GC-MS confirmation analysis, the extraction protocol consisted of an alkaline LLE using borate buffer and a mixture of toluene, hexane and isoamyl alcohol (78:20:2). Back extraction into ethyl acetate was performed using sulfuric acid and neutralization with $\mathrm{NaHCO} / \mathrm{K}_{2} \mathrm{CO}_{3}$. In case 1, heart blood immunoassay screening was presumptive positive for fentanyl and opiates, but confirmation testing were negative. Submitting the drug paraphernalia to the screening procedure, positive results were obtained for the presence of fentanyl analogues, including carfentanil, furanylfentanyl and parafluoroisobutyrfentanyl. The presence of carfentanil $(1.3 \mathrm{ng} / \mathrm{mL})$ and furanylfentanyl $(0.34 \mathrm{ng} / \mathrm{mL})$ was then confirmed in heart blood by a reference laboratory. In the second case, immunoassay screening was negative for the presence of fentanyl, but urine GC-MS screening revealed the presence of carfentanil. Also in this case, the presence of carfentanil at low levels $(0.12 \mathrm{ng} / \mathrm{mL})$ was confirmed in heart blood by a reference laboratory.

Several recent fatality cases associated with the use of carfentanil were reported by Shanks and Behonick [20]. Carfentanil was typically detected and quantified in $250 \mu \mathrm{L}$ whole blood specimens via a simple protein precipitation extraction with acetonitrile and LC-MS/MS. ESI combined with triple quadrupole 
MS/MS was performed in the positive ionization SRM mode. The optimized ion transitions for carfentanil were $395.1 \rightarrow 112.5$ (quantifying transition) and $395.1 \rightarrow 334.9$ (qualifying transition), which provided LOD and LOQ values as low as 5 and $10 \mathrm{pg} / \mathrm{mL}$, respectively, and a calibration curve extending in the interval 5$25,000 \mathrm{pg} / \mathrm{mL}$. Carfentanil was detected in 13 intoxication cases at very low levels: the observed whole blood concentration ranged between 10 and $617 \mathrm{pg} / \mathrm{mL}(0.01-0.617 \mathrm{ng} / \mathrm{mL})$.

\section{Ocfentanil}

Ocfentanil (N-(2-fluorophenyl)-2-methoxy-N-[1-(2-phenylethyl)piperidin-4-yl] acetamide) is an opioid analgesic developed in the early 1990s and structurally similar to fentanyl. Also its pharmacological effects are similar to fentanyl, as it produces strong analgesia and sedation, with a slightly more potent action [23]. Although octafentanil has never been approved for any medical use, it has recently been detected in the hidden market as an adulterant of heroin [24].

Coopman et al. reported an ocfentanil overdose fatality occurred to a 17-years old young man with a history of illegal substance abuse [25]. The initial systematic toxicological analysis on body fluids revealed only the presence of acetaminophen and caffeine in blood, urine, and stomach content. A brown powder found in the proximity of the victim was collected and analyzed by HPLC with photodiode array detector and GC-MS in full scan mode. Ocfentanil was identified in the powder by computer based MS-library comparison with of the SWGDRUG MS Library. Subsequently, a targeted method was developed to quantify ocfentanil in the biological samples, which was based on LLE and UHPLC-MS/MS. The biological samples were extracted with a mixture of $n$-hexane:ethyl acetate $(7: 3, v / v)$, after alkalization with potassium carbonate. Detection was carried out using a triple quadrupole MS/MS instrument equipped with an ESI source operating in positive ion mode. The SRM transitions used for ocfentanil quantitation were $\mathrm{m} / \mathrm{z} 371.00 \rightarrow 188.00 \mathrm{and} \mathrm{m} / \mathrm{z}$ $371.00 \rightarrow 105.00$. The LOQ of the method was set as the lowest non-zero calibrator concentration (2.1 $\mathrm{ng} / \mathrm{mL}$ ). The concentrations found in cardiac blood collected at the autopsy were $23.3 \mathrm{ng} / \mathrm{mL}$ (tube with EDTA as preservative) and $21.9 \mathrm{ng} / \mathrm{mL}$ (tube without preservative).

A similar intoxication case reported by Dussy et al. [26] was also oriented by a brown powder found close to the victim and submitted to the toxicological analysis, which revealed the presence of ocfentanil. The 
subsequent instrumental analysis was addressed to the selective detection of ocfentanil in the biological specimens and made use of a LC-MS/MS experiment conducted with a linear ion trap and atmosphericpressure chemical ionization (APCI). Four different approaches were used for the quantification of ocfentanil in blood and urine. The first approach was based on an external calibration built on blank serum fortified with three fentanyl concentrations and brotizolam as the internal standard. The second approach used a modified internal calibration method, in which peripheral whole blood sample of the deceased was fortified with three fentanyl concentrations. The ocfentanil concentration was estimated assuming again equal response factors for fentanyl and ocfentanil along the investigated concentration range. In the third approach, estimation of the ocfentanil concentration was obtained by by external calibration using blank serum samples fortified with ocfentanil at eight concentrations and fentanyl as the internal standard. The last approach used the standard addition method, in which the biological specimen was fortified with three concentrations of ocfentanil and the quantification was obtained from the projection of the standard addition calibration line on the $\mathrm{x}$-axis. The results of the four approaches for the estimation of the ocfentanil concentration in femoral whole blood proved not to differ significantly and were in agreement within the experimental error. The final ocfentanil concentration in whole blood was reported in the interval 7.2-9.3 ng/mL.

\section{OTHER OPIOIDS}

\section{AH-7921}

AH-7921, (3,4-dichloro-N-\{[1-(dimethylamino)cyclohexyl] methyl $\}$ benzamide) is a potent opioid analgesic agent with pharmacological activity similar to morphine that was synthesized and patented in the mid-1970s, but never registered and marketed for human consumption [15]. AH-7921 was first identified in Europe in a sample purchased from an internet retailer in July 2012, and sold as both free base and hydrochloride salt in a white/off-white powder form [27]. It is generally acquired from various internet websites where it is sometimes referred to as 'Doxylam' [28].

One of the first fatal intoxication case involving AH-7921 was reported in 2014 by Vorce et al. [29]. Preliminary screening analysis was conducted on urine by immunoassay and was addressed to the detection 
of the most common drugs of abuse. A second screening was carried out by GC-MS for alkaline-extractable drugs, with the mass spectrometer operating in full scan mode. AH-7921 was identified in the urine sample by comparing its GC-MS mass spectrum with those present in the Laboratory's internal MS library. For the confirmatory quantitative analysis, an alkaline LLE procedure was used to isolate AH-7921 from various sample matrices followed by GC-SIM-MS analysis, using the selected ions m/z 126 (quantifier), 173 and 145 (qualifiers) and MDPV- $d_{8}$ as the internal standard. The heart blood had an AH-7921 concentration of 3.9 $\mathrm{mg} / \mathrm{L}$ and the peripheral blood concentration was $9.1 \mathrm{mg} / \mathrm{L}$. Moreover The following concentrations of AH7921 were reported for the various organs: $6.0 \mathrm{mg} / \mathrm{L}$ in urine, $26 \mathrm{mg} / \mathrm{kg}$ in liver, $7.2 \mathrm{mg} / \mathrm{kg}$ in kidney, 8.0 $\mathrm{mg} / \mathrm{kg}$ in spleen, $5.1 \mathrm{mg} / \mathrm{kg}$ in heart, $21 \mathrm{mg} / \mathrm{kg}$ in lung, $7.7 \mathrm{mg} / \mathrm{kg}$ in brain, $17 \mathrm{mg} / \mathrm{L}$ in bile and $120 \mathrm{mg} / 125$ $\mathrm{mL}$ in the stomach content.

AH-7921 was found in combination with other substances in the biological fluids arising from two intoxication cases described by Karinen et al. [30]. Post-mortem whole blood samples were submitted to UHPLC-MS/MS analysis, using several methods for the detection of multiple pharmaceutical drugs and common drugs of abuse. An untargeted Q-TOF LC-MS run was also performed to complete the screening. In both intoxication cases, the high-resolution MS analysis revealed a signal with exact mass compatible with the AH-7921 molecular formula. For confirmation, blood samples were extracted by LLE under alkaline conditions $(\mathrm{pH} 11)$, with borate buffer and a ethylacetate/heptane mixture. Instrumental analyses were executed by UHPLC-MS/MS with a Z-spray electrospray ionization interface operating in the positive ionization mode. A SRM protocol was developed for the quantification of AH-7921 based on the transitions $\mathrm{m} / \mathrm{z} 329.2 \rightarrow 284.2$ and $329.2 \rightarrow 144.9$. The observed AH-7921 blood concentrations were $0.43 \mathrm{mg} / \mathrm{L}$ (case 1 ) and $0.33 \mathrm{mg} / \mathrm{L}$ (case 2 ). In both cases several NPS were also found in body fluids.

A series of nine fatal intoxication cases associated with AH-7921 were reported by Kronstrand et al. [31]. Routine postmortem toxicology examination was performed on femoral blood using a targeted screening for pharmaceuticals and drugs of abuse developed on LC-TOF-MS instrumentation. An in-house database comprising nearly 550 drugs was used for the determination of target compounds primarily relevant in postmortem toxicology. The presence of AH-7921 was subsequently confirmed by LC-MS/MS experiments. Proteins were precipitated from the blood samples with a mixture of acetonitrile: ethanol $(90: 10)$ acidified 
with of $0.075 \%$ formic acid. The extract was then injected into the LC-MS/MS triple-quadrupole system equipped with ESI source operating in the positive ion mode. For the LC separation, the mobile phase A was $0.05 \%$ formic acid in $10 \mathrm{mM}$ ammonium formate and phase B was $0.05 \%$ formic acid in methanol with a linear gradient from $5 \% \mathrm{~B}$ to $70 \% \mathrm{~B}$ within $3 \mathrm{~min}$ at a total flow of $0.5 \mathrm{~mL} / \mathrm{min}$. Two transitions were monitored for AH-7921 $(329 \rightarrow 284$ and $329 \rightarrow 173)$ and one transition for the internal standard EDDP- $d_{3}$ $(282 \rightarrow 235)$. The authors recorded AH-7921 concentrations in blood ranging from 0.03 to $0.99 \mu \mathrm{g} / \mathrm{g}$.

An approach based on LC-QTOF-MS technique was used in a recent fatal case involving AH-7921 and described by Fels et al. [32]. AH-7921 was determined in femoral blood after a simple protein precipitation with acetonitrile. The MS experimental conditions included positive electrospray ionization with a DuoSpray ion source, mass resolution of the TOF analyzer set to 30,000 in the single-MS mode and 15,000 in product ion scanning (high sensitivity mode). Quantification of AH-7921 was executed in urine, pericardial fluid, vitreous humor, and gastric content. A calibration curve at six AH-7921 concentrations was build in urine to cover a range from 100 to $5000 \mathrm{ng} / \mathrm{mL}$. The concentration of $\mathrm{AH}-7921$ in femoral blood was equal to 450 $\mathrm{ng} / \mathrm{mL}$.

\section{U-47700}

U-47700 (3,4-dichloro-N-[2-(dimethyloamino)cyclohexyl]- N-methylbenzamide) is an opioid analgesic drug that was developed by Upjohn in the 1970s [33]. U-47700 has been studied only in animals, and it was found to be 7.5 times more potent than morphine [34]. It was never studied in humans or marketed as a pharmaceutical and medicinal drug for human use [35]. U-47700 was derived from the opioid AH-7921as a structural isomer of it. The compound is gaining popularity among drug users as a legal alternative to morphine/heroin and is typically sold in the illegal market as a white powder. Its administration routes include oral and intrarectal absorption, snorting, smoking, intravenous injection, or combinations of these routes [15]. Its use has been reported in the Unites States, Europe, Australia, and Japan wherever leading to intoxications and fatalities [36].

McIntyre et al. quantified U-47700 in several matrices by GC-MS after a double LLE with 1-chlorobutane and alkalization with concentrated ammonium hydroxide [37]. Presumptive identification of U-47700 was initially carried out in the peripheral blood using an alkaline drug screening with GC-MS in scan mode, after 
SPE. The drug was subsequently confirmed and quantified by GC-SIM-MS analysis by monitoring the ions $\mathrm{m} / \mathrm{z} 84$ (quantifier), 125, and 110, and using hydrocodone- $d_{3}$ as the internal standard. LOD and LOQ values of 5 and $20 \mathrm{ng} / \mathrm{mL}$, respectively, were determined. The U-47700 peripheral blood concentration was quantified at $190 \mathrm{ng} / \mathrm{mL}$ and compared with the detected central blood concentration of $340 \mathrm{ng} / \mathrm{mL}$. Further presence of U-47700 was determined in liver (1,700 ng/g), vitreous humour (170 ng/mL), urine (360 ng/mL). and gastric content at trace amount $(<1 \mathrm{mg})$.

Another fatal intoxication case involving U-47700 was reported by Elliot et al. [38]. In this case a qualitative screening based on HPLC-DAD, HPLC-MS, and UHPLC-QTOF-MS analysis were performed after LLE with 1-chlorobutane. The concomitant application of these techniques made it possible to differentiate U47700 from its isobaric compound AH-7921. As a matter of fact, triple quadrupole/linear ion trap LC-MS analysis showed that U-47700 and AH-7921 shared both the precursor and some primary product ions, such as $\mathrm{m} / \mathrm{z} 145,173$, and 284 . The only product ions that allowed the differentiation of the two isomers were found at m/z 204 and 81 (U-47700), and m/z 190 and 95 (AH-7921), respectively. Quantitative analysis of U-47700 was performed by a validated HPLC-DAD method. A LOD of $50 \mathrm{ng} / \mathrm{mL}$ and a LOQ of $312 \mathrm{ng} / \mathrm{mL}$ were extrapolated from the signal obtained from the lowest calibrator. U-47700 was subsequently measured in real biological samples, showing a concentration of $1,460 \mathrm{ng} / \mathrm{mL}$ in post-mortem femoral blood.

Jones et al. described a fatal U-47700 overdose case that occurred after a product called "U4" was consumed by nasal insufflation and injection [39]. Screening analysis was initially performed on an urine sample using an untargeted UHPLC-TOF-MS procedure and collecting full spectrum and high-resolution MS data with and without collision-induced fragmentation. The results were consistent with the presence of U-47700 and related designer opiates, together with other opiates, drugs of abuse, and non-opiate pharmaceuticals. With the same technique, U-47700 was quantified in urine and serum samples using response ratios vs. the isotopically-labeled AH-7921- $d_{3}$ internal standard in comparison with calibrators fortified with U-47700. The U-47700 parent compound was detected at $394 \mathrm{ng} / \mathrm{mL}$ and $228 \mathrm{ng} / \mathrm{mL}$ levels in serum and urine, respectively.

Another fatal intoxication case involved the concomitant use of U-47700 and fentanyl [40]. Using the same approach previously described for ocfentanyl [25], U-47700 was quantified in post-mortem blood and urine 
at a concentration of 13.8 and $71 \mathrm{ng} / \mathrm{mL}$ respectively. Detection was carried out using a triple quadrupole MS equipped with an ESI source operating in the positive ion mode. The SRM transitions used for the determination of U-47700 were $330.20 \rightarrow 285.20$ (qualifier) and $330.20 \rightarrow 173.20$. The LOQ of the method was defined as the lowest non-zero calibrator concentration $(1.6 \mathrm{ng} / \mathrm{mL})$.

Mohr et al. developed a LC-MS/MS method for the for the simultaneous analysis of U-47700, U-50488 and furanyl-fentanyl in blood specimens [35]. The method was applied in 20 postmortem cases initially attributed to heroin or other opioid-related drug overdoses. For quantitative analysis, the samples were treated with phosphate buffer at $\mathrm{pH}$ 6, extracted by SPE and then eluted with a mixture of ethyl acetate/acetonitrile/ammonium hydroxide (78:20:2). Only U-47700 was found in 11 out of 20 cases. In 5 cases, the presence of both U-47700 and furanyl-fentanyl was confirmed, while in 3 cases only the presence of furanyl-fentanyl was confirmed. The U-47700 concentration in blood was in the interval $17-490 \mathrm{ng} / \mathrm{mL}$ while the furanyl-fentanyl concentration was in the range $2.5-76 \mathrm{ng} / \mathrm{mL}$.

\section{MT-45}

MT-45 (1-cyclohexyl-4-(1,2-diphenylethyl)piperazine) was developed in the '70s in Japan, as an alternative to morphine for analgesia [41], but it was never marketed as a prescription drug. Nowadays, it is typically sold as a "research chemical" on the internet market and was also identified in chemical and herbal products along with synthetic cannabinoids, cathinones and a phenethylamine derivative [32].

Papsun et al. reported a fatal case intoxication involving MT-45 [42] after the use of two powders allegedly containing MT-45 and etizolam, respectively. An alkaline LLE extraction procedure was used to isolate MT45 from the whole blood. A mixture of n-butylchloride/acetonitrile $(4: 1 \mathrm{v} / \mathrm{v})$ was used as the extraction solvent. A comprehensive toxicology drug screening was performed on whole blood by HPLC-TOF-MS, while urine samples were submitted to an ELISA immunoassay screening for the presence of the most common drugs of abuse. MT-45 was not detected with the latter technique since it demonstrated no crossreactivity with the opiate immunoassay plates. Targeted analysis of MT-45 in femoral blood was performed by UHPLC-MS/MS with the MS operating in the positive electrospray and SRM mode. The SRM transitions used for the quantification of MT-45 were $\mathrm{m} / \mathrm{z} 349.3 \rightarrow 181.1$ (quantifier) and $349.3 \rightarrow 169.2$ (qualifier). 
Acetylfentanyl- $d_{5}$ was used as the internal standard. Quantification was performed by the standard addition method, yielding a MT-45 concentration in the decedent's blood equal to $520 \mathrm{ng} / \mathrm{mL}$.

Another fatal intoxication case involving the concomitant use of MT-45 was recently described [32]. Using the same approach described for the detection of AH-7921 and a 7-point calibration curve ranging from 10 to 5,000 ng/mL, MT-45 was quantified in several post-mortem specimens. In femoral blood MT-45 was detected at a $2,900 \mathrm{ng} / \mathrm{mL}$ concentration.

\section{MULTITARGET APPROACHES}

A UHPLC-MS/MS method for the simultaneous determination of acetylfentanyl, acetylnorfentanyl and butyrfentanyl in post mortem specimens was developed by Poklis et al. [43]. Samples extraction by SPE used a 78:20:2 dichloromethane/isopropanol/ammonia (v:v:v) mixture as the elution solvent. The analytes were separated by UHPLC in a chromatographic run of 4 min and detected by a triple quadrupole analyzer operating in SRM. For LC separation, the mobile phase consisted of (A) water/10 $\mathrm{mM}$ ammonium formate/ $0.1 \%$ formic acid and (B) methanol. The following gradient was used: $0.00-1.5$ min at $95 \% \mathrm{~A}$ and $5 \% \mathrm{~B}, 1.5-3 \mathrm{~min}$ at $60 \% \mathrm{~A}$ and $40 \% \mathrm{~B}, 3-3.5 \mathrm{~min}$ at $100 \% \mathrm{~B}$ and then return to $95 \% \mathrm{~A}$ and $5 \% \mathrm{~B}$ at $3.6 \mathrm{~min}$. The flow rate was $0.6 \mathrm{~mL} / \mathrm{min}$. The method was then applied to two fatal intoxications allegedly involving synthetic opioids. In the first case, butyrfentanyl was detected in different matrices, among which peripheral blood, at $99 \mathrm{ng} / \mathrm{mL}$ concentration. In the second case, butyrfentanyl was found in peripheral blood, together with acetylfentanyl and acetylnorfentanyl at concentrations of 3.7, 21 and $<1 \mathrm{ng} / \mathrm{mL}$, respectively.

Using the same extraction protocol, a sensitive LC-MS/MS method was addressed to the simultaneous determination of carfentanil, 3-methylfentanyl, 2-furanylfentanyl, acetylfentanyl, fentanyl and norfentanyl in biological samples [44]. The analytes were detected by a triple quadrupole MS equipped with a ESI ion source operating in the positive ion mode. The proposed method proved adequate for the detection of synthetic opioids at low level in blood specimens, showing LOD values in the range $0.1-1.0 \mathrm{ng} / \mathrm{mL}$. The method was successfully applied in both postmortem and impaired-driving cases. 
Shoff et al. recently published a work describing a comprehensive and sensitive screening method using UHPLC-ion trap MS with MS $^{\mathrm{n}}$ capabilities to identify illicit substances and common prescription analgesics in postmortem biological fluids and tissues [45]. Fifteen substances, among synthetic opioids and metabolites, were included in the method. Electrospray ionization with alternating polarity was employed to detect both positive and negative ions. $\mathrm{MS}^{\mathrm{n}}$ experiments allowed to increase the specificity and sensitivity of detection, producing LOD values in the range $0.1-0.5 \mathrm{ng} / \mathrm{mL}$.

\section{CONCLUSIONS}

Clinical and forensic toxicologists must remain vigilant as various new synthetic opioids continuously appear, so new analytical methods for the identification and determination of such substances and their metabolites are needed in intoxication or postmortem cases.. In particular, the capability of simultaneous multi-target analysis is essential in broad drug screening of unknown analytes, because in most acute intoxications and post-mortem investigations the ingested substance cannot be anticipated. GC-MS technique is still a well-established method for systematic toxicological analysis (STA) of human body fluids. Nevertheless, often these potent synthetic opioids are present at very low levels $(<10 \mathrm{ng} / \mathrm{mL})$ making difficult their identification. For this reason, there is a clear trend to replace existing GC-MS procedures with LC-MS/MS assays. In LC-MS-based approach, standard procedures provide minimal LOD and LOQ values, often with minimal sample treatment. Furthermore, modern UHPLC-MS/MS instruments with triplequadrupole analyzers can simultaneously detect more than one hundred substances in just a few minutes, and generally the methods are sufficiently flexible to include new substances and more Internal Standards, for a continuously expanding set of analytes. However, intoxication cases caused by synthetic opioids may be related to new compounds for which neither reference standards or published literature are available. In this context, the introduction of performing high-resolution mass spectrometers, can make the laboratory capable of executing a truly general toxicological analysis on biological samples, allowing factual untargeted screening and retrospective reexamination of acquired data, following the identification (or the reporting from the National Early Warning Systems) of new designer opioids. 


\section{REFERENCES}

[1] Prekupec, M.P.; Mansky, P.A.; Baumann, M.H. Misuse of Novel Synthetic Opioids: A Deadly New Trend. J Addict. Med, 2017, 11, 256-265.

[2] European Monitoring Centre for Drugs and Drug Addiction. European Drug Report. Trends and developments 2015. http://www.emcdda.europa.eu/system/files/publications/974/TDAT15001ENN.pdf. Accessed 7 August 2017.

[3] Palamar, J.J.; Salomone, A.; Vincenti, M.; Cleland, C.M. Detection of "bath salts" and other novel psychoactive substances in hair samples of ecstasy/MDMA/“Molly" users. Drug Alcohol Depend., 2016, 161, 200-205.

[4] Palamar, J.J.; Salomone, A.; Gerace, E.; Di Corcia, D.; Vincenti, M.; Cleland, C.M. Hair testing to assess both known and unknown use of drugs amongst ecstasy users in the electronic dance music scene. Int. J. Drug Policy, 2017, 48, 91-98.

[5] United Nations Office on Drugs and Crime. November 2016 - UNODC: Deaths Associated with Use of merging Synthetic Opioids. https://www.unodc.org/LSS/Announcement/Details/466aa396-492d-4129a1bc-f519ecb5d443. Accessed 7 August 2017.

[6] World Health Organization. Acetylfentanyl, Critical review report. Agenda item 5.2. Expert Committee on Drug Dependence. http://www.who.int/medicines/access/controlled-substances/ecdd/en/. Accessed 8 August 2017.

[7] Drug Enforcement Administration. Schedules of controlled substances: temporary placement of acetyl fentanyl into Schedule I. Fed. Regist, 2015, 80, 42381-42385.

[8] Katselou, M.; Papoutsis, I.; Nikolaou, P.; Spiliopoulou, C.; Athanaselis, S. Old opioids, new concerns: the case of acetylfentanyl. Forensic Toxicol., 2016, 34, 201-212. 
[9] Mcintyre, I.M.; Trochta, A.; Gary, R.D.; Malamatos, M.; Lucas, J.R. An Acute Acetyl Fentanyl Fatality: A Case Report With Postmortem Concentrations. J. Anal. Toxicol., 2015, 39, 490-494.

[10] Fort, C.; Curtis, B.; Nichols, C.; Niblo, C. Acetyl Fentanyl Toxicity: Two Case Reports. J. Anal. Toxicol., 40, 2016, 754-757.

[11] Takase, I.; Koizumi, T.; Fujimoto, I.; Yanai, A.; Fujimiya, T. An autopsy case of acetyl fentanyl intoxication caused by insufflation of "designer drugs". Leg. Med., 2016, 21, 38-44.

[12] Yonemitsu, K.; Sasao, A.; Mishima, S.; Ohtsu, Y.; Nishitani, Y. A fatal poisoning case by intravenous injection of "bath salts" containing acetyl fentanyl and 4-methoxy PV8. Forensic Sci. Int., 2016, 267, e6-e9.

[13] Cunningham, S.M,; Haikal, N.A,; Kraner, J.C. Fatal Intoxication with Acetyl Fentanyl. J. Forensic Sci., 2016, 61, 276-280.

[14] Guerrieri, D.; Rapp, E.; Roman, M.; Thelander, G.; Kronstrand, R. Acrylfentanyl: Another new psychoactive drug with fatal consequences. Forensic Sci. Int., 2017, 277, e21-e29.

[15] Zawilska, J.B. An expanding world of Novel Psychoactive Substances: Opioids. Front. Psychiatry, 2017, 8, 2-14.

[16] Bäckberg, M.; Beck, O.; Jönsson, K.; Helander, A. Opioid intoxications involving butyrfentanyl, 4-fluorobutyrfentanyl, and fentanyl from the Swedish STRIDA project. Clin.Toxicol., 2015, 53, 609-617.

[17] Staeheli, S.N.; Baumgartner, M.R.; Gauthier, S.; Gascho, D.; Jarmer, J.; Kraemer, T.; Steuer, A.E. Time-dependent postmortem redistribution of butyrfentanyl and its metabolites in blood and alternative matrices in a case of butyrfentanyl intoxication. Forensic Sci. Int., 2016, 266, 170-177.

[18] Mcintyre, I.M.; Trochta, A.; Gary, R.D.; Wright, J.; An Acute Butyr-Fentanyl Fatality: A Case Report with Postmortem Concentrations. J. Anal. Toxicol., 2016, 40, 162-166.

[19] Rojkiewicz, M.; Majchrzak, M.; Identification and physicochemical characterization of 4fluorobutyrfentanyl and post-mortem biological samples. Drug Test. Analysis. 2017, 9, 405-414. 
[20] Shanks, K.G.; Behonick, G.S. Detection of Carfentanil by LC-MS-MS and Reports of Associated Fatalities in the USA. J. Anal. Toxicol., 2017, 41, 466-472.

[21] Guerrieri, D.; Rapp, E.; Roman, M.; Druid, H.; Kronstrand, R. Postmortem and Toxicological Findings in a Series of Furanylfentanyl-Related Deaths. J. Anal. Toxicol., 2017, 41, 242-249.

[22] Swanson, D.M.; Hair, L.S.; Rivers, S.R.S., Smyth, B.C.; Smyth, B.C.; Brogan, S.C.; Ventoso, A.D.; Vaccaro, S.L.; Pearson, J.M. Case Report Fatalities Involving Carfentanil and Furanyl Fentanyl: Two Case Reports. J. Anal. Toxicol., 2017, 41, 498-502.

[23] Scientific Institute of Public Health, Belgian Early Warning System Drugs. Fact Sheet Ocfentanil, May 2017. http://www.vad.be/assets/2635. Accessed 21 August 2017.

[24] Quintana, P.; Ventura, M,; Grifell, M.; Palma, A.; Galindo, L.; Fornís, I.; Gil, C.; Carbón, X.; Caudevilla, F.; Farré, M.; Torrens, M. The hidden web and the fentanyl problem: detection of ocfentanil as an adulterant in heroin. Int J Drug Policy. 2016, 40, 78-83

[25] Coopman, V.; Cordonnier, J.; De Leeuw, M.; Cirimele, V. Ocfentanil overdose fatality in the recreational drug scene. Forensic Sci. Int. 2016, 266, 469-473.

[26] Dussy, F.E.; Hangartner, S.; Hamberg, C.; Berchtold, C.; Scherer, U.; Schlotterbeck, G.; Wyler, D.; Briellmann, T.A. An Acute Ocfentanil Fatality: A Case Report with Postmortem Concentrations. J. Anal. Toxicol., 2016, 40, 761-766.

[27] European Monitoring Centre for Drugs and Drug Addiction.. EMCDDA-Europol Joint Report on a New Psychoactive Substance: AH-7921. http://www.emcdda.europa.eu/system/files/publications/816/AH7921_465209.pdf. Accessed 7 August 2017.

[28] Katselou, M.; Papoutsis, I. AH-7921: the list of new psychoactive opioids is expanded. Forensic Toxicol. 2015, 33, 195-201.

[29] Vorce, S.P.; Knittel, J.L.; Holler, J.M.; Magluilo, J.; Levine, B.; Berran, P.; Bosy, T.Z. A Fatality Involving AH-7921. J. Anal. Toxicol., 2014, 38, 226-230. 
[30] Karinen, R.; Skogstad, S.; Rogde, S.; Dadalto Peres, M.; Johansen, U.; Frost, J.; Vindenes, V.; Øiestad, A.M.L. Lethal poisonings with AH-7921 in combination with other substances. Forensic Sci. Int. 2014, 244, 24-27.

[31] Kronstrand, R., Thelander, G., Lindstedt, D., Roman, M., Kugelberg, F.C. Fatal Intoxications Associated with the Designer Opioid AH-7921. J. Anal. Toxicol., 2014, 38, 599-604.

[32] Fels, H., Krueger, J., Sachs, H., Musshoff, F., Graw, M. Two fatalities associated with synthetic opioids: AH-7921 and MT-45. Forensic Sci. Int. 2017, 277, e30-e35.

[33] Scientific Institute of Public Health, Belgian Early Warning System Drugs. Fact Sheet U-47700, May 2017. http://www.vad.be/assets/2637. Accessed 21 August 2017.

[34] Cheney, B.V.; Szmuszkovicz, J.; Lahti, R.A.; Zichi, D.A. Factors affecting binding of trans-N-[2methylamino)cyclohexyl]benzamides at the primary morphine receptor. J. Med. Chem. 1985, 28, 18531864.

[35] Mohr, A.L.A.; Friscia, M.; Papsun, D.; Kacinko, S.L.; Buzby, D.; Logan, B.K. Analysis of Novel Synthetic Opioids U-47700, U-50488 and Furanyl Fentanyl by LC-MS/MS in Postmortem Casework. $J$. Anal. Toxicol., 2016, 45, 709-717.

[36] Nikolaou, P.; Katselou, M.; Papoutsis, I.; Spiliopoulou, C. U-47700. An old opioid becomes a recent danger. Forensic Toxicol. 2017, 35, 11-19.

[37] Mcintyre, I.M.; Gary, R.D.; Joseph, S.; Stabley, R. A Fatality Related to the Synthetic Opioid U47700: Postmortem Concentration Distribution. J. Anal. Toxicol., 2017, 41, 158-160.

[38] Elliott, S.P.; Brandt, D.; Smith, C. The first reported fatality associated with the synthetic opioid 3,4dichloro-N-[2-(dimethylamino)cyclohexyl]-N-methylbenzamide (U-47700) and implications for forensic analysis. Drug Test. Analysis. 2016, 8, 875-879.

[39] Jones, M.J.; Hernandez, B.S.; Janis, G.C.; Stellpflug, S.J. A case of U-47700 overdose with laboratory confirmation and metabolite identification. Clin. Toxicol., 2017, 55, 55-59. 
[40] Coopman, V.; Blanckaert, P.; Van Parys, G.; Van Calenbergh, S.; Cordonnier, J. A case of acute intoxication due to combined use of fentanyl and 3,4-dichloro-N-[2-(dimethylamino)cyclohexyl]-Nmethylbenzamide (U-47700). Forensic Sci. Int. 2016, 266, 68-72.

[41] Zhu, Y.Q.; Ge, G.L.; Fang, S.N.; Zhu, Y.C.; Dai, Q.Y.; Tan, Z.Y. Studies on potent analgesics. I. Synthesis and analgesic activity of derivatives of fentanyl (author's transl), Acta Pharmacol. Sin., 1981, 16, 199-210

[42] Papsun, D.; Krywanczyk, A.; Vose, J.C.; Bundock, E.A.; Logan, B.K. Case Report Analysis of MT45, a Novel Synthetic Opioid, in Human Whole Blood by LC-MS-MS and Its Identification in a DrugRelated Death. J. Anal. Toxicol., 2016, 40, 313-317.

[43] Poklis, J.; Poklis, A.; Wolf, C.; Hathaway, C.; Arbefeville, E.; Chrostowski, L.; Devers, K.; Hair, L.; Mainland, M.; Merves, M.; Pearson, J. Two Fatal Intoxications Involving Butyryl Fentanyl. J. Anal. Toxicol., 2016, 40, 703-708.

[44] Sofalvi, S.; Schueler, H.E.; Lavins, E.S.; Kaspar, C.K.; Brooker, I.T.; Mazzola, C.D.; Dolinak, D.; Gilson, T.P; Perch, S. An LC-MS-MS Method for the Analysis of Norfentanyl in Postmortem and ImpairedDriving Cases. J. Anal. Toxicol., 2017, 41, 473-483.

[45] Shoff, E.N.; Zaney, M.E.; Kahl, J.H.; Hime, G.W.; Boland, D.M. Qualitative Identification of Fentanyl Analogs and Other Opioids in Postmortem Cases by UHPLC-Ion Trap-MS. J. Anal. Toxicol., 2017, $41,484-492$. 